\title{
NOVAS TECNOLOGIAS REPRODUTIVAS CONCEPTIVAS: O PARADOXO DA VIDA E DA MORTE
} New Reproductive Technologies for Conception: the paradox of life and death

Marlene Tamanini*

\section{Resumo}

Analisam-se nesse texto algumas das várias questões críticas, que podem ser encontradas no uso das novas Tecnologias Reprodutivas Conceptivas. Ressaltam-se as posições feministas no que se refere às mesmas, e ao apresentá-las e contrapô-las com duas situações ocorridas com as mães e com as crianças, elege-se um leque de disposições valorativas que problematizam o uso indiscriminado das práticas de reprodução humana em laboratório. Aponta-se para a necessidade de construir um entendimento compreensivo que atenda a ampliação de outros fatores, como aqueles associados à abertura para o risco da parte dos médicos e casais e a instrumentalização das dimensões subjetivas e simbólicas que influenciam na projeção de um sentido para a vida, por meio da busca pelo filho por meio de tecnologia.

Palavras-chave: reprodução, instrumentalização, riscos.

\section{Abstract}

This text analyzes several critical issues that emerge around the use of new reproductive technologies for conception. Particular emphasis is given to feminist positions, which are presented and counterposed in two different

* Doutora em Ciências Humanas, professora do Departamento de Ciências Sociais da Universidade Federal do Paraná, membro do grupo de pesquisa Estudos de Gênero e do grupo Trabalho e Sociedade. 
situations regarding mothers and children. This is carried out through a value framework that problematizes the indiscriminate use of laboratory practices for human reproduction. Attention is drawn to the need to develop a comprehensive understanding of factors such as the risks assumed by doctors and couples, and the instrumentalization of subjective and symbolic dimensions that influence the meanings given to life in the search to conceive a child through technological means.

Keywords:" reproduction, instrumentalization, risks.

Quando confrontados com a experiência da infertilidade ${ }^{1}$, homens e mulheres vivendo em comum, não importando se heterossexuais ou homossexuais, são mobilizados a buscar uma solução para a ausência de filhos. Ainda que os padrões que sancionam a elegibilidade sejam diferentes em se tratando de uns e de outros ${ }^{2}$. Na experiência do limite, da pressão e da resistência exteriorizam sua disponibilidade de solução, no momento em que se encontram com o mundo de sua vida e a proposta biomédica/tecnológica. O problema é que nem sempre a conhecem, e ao exporem sua tamanha necessidade desencadeiam desejos de solução e possibilidades de intervenções tais, que se torna difícil concretizar qualquer tentativa de dissuasão vinda de fora dessa relação. Agrava-se a vulnerabilidade ao risco quando, em suas vivências, os casais, ao carregarem os sentidos da imediatez e das estratégias intencionadas, como seguir o caminho proposto pelo médic@ ${ }^{3}$ para alçarem a posse de uma experiência duradoura que é a busca de conviver com um filho, se deparam com situações paradoxais e inusitadas e acabam por autorizar instâncias exteriores a tomarem decisões por eles. Ou ainda, são colocados em situações tais, que já não conseguem dizer nada, a não ser sofrerem as consequiências dos atos desencadeados às vezes por eles e,

1 A infertilidade, seja masculina ou feminina, define-se como a impossibilidade de um dos cônjuges para gerar um filho.

2 DINIZ, Déborah; COSTA, Rosely Gomes, 2005.

$3 \mathrm{O}$ arroba será utilizado em relação ao médico/a para neutralizar o sexo e focar o campo da biomedicina que neste caso interage com suas representações, seu simbólico e sua prática o que no meu estudo, independe do gênero do profissional. 
na maioria das vezes, pela ambição de sucesso que pode se dar em condições em que as decisões sobre a prática é realizada somente a partir da clinica e dos seus profissionais, com pouca ou minorizada decisão do casal e da mulher.

A reprodução assistida, por sua vez, já é oferecida no contexto de um quadro de aliados que acumula recursos sociais, econômicos e tecnocientíficos, amalgamados aos modelos da maternidade e da paternidade biológicas que, por sua vez, articulam conteúdos cognitivos e sociais, e conectam linguagens performativas, sob critérios capazes de invocar a eficácia, o pragmatismo e o desejo.

Grande parte dessas questões foram explicitadas pelo movimento feminista, Estado, Igreja, juristas, médic@, cientistas, demógraf@s, filósof@s e pela sociedade civil. A vertente teórica mais influente que as orientou em relação a concepção, o aborto e as técnicas conceptivas na América Latina, provém das mais distintas correntes da crítica feminista e se fundamenta nos campos da saúde reprodutiva, dos direitos reprodutivos e da bioética, analisados pela ótica das relações sociais de sexo e de gênero.

Permaneceram, porém, em aberto, questões sobre as circunstâncias que justificam abandonar a autonomia sexual e propor uma assistência médica com ou não fecundação, e abriu-se algum caminho para visualizar quais são os limites da responsabilidade médica em casos nos quais há riscos para a mulher e para as crianças, problemas que serão apresentados na segunda parte desse texto.

\section{MAPEANDO POSIÇÕES FEMINISTAS}

Para mapear as posições assumidas pelo movimento feminista, consideram-se aspectos desenvolvidos por teóric@s e militantes no Brasil e na França, que são um pouco representantes de posturas encontradas em várias pensador@s, também em outras partes do mundo.

Segundo Laborie 4 , pode-se identificar dois tipos de posicionamentos entre as feministas francesas. Um primeiro tipo, aquelas que se opõem 
as tecnologias reprodutivas por razões de princípio. Para estas, as novas tecnologias reprodutivas conceptivas (NTRc) supõem o aumento do controle masculino sobre um território até então feminino - a maternidade. A abordagem técnica da gravidez parte do modelo masculino de produção de milhões de espermatozóides; para tanto as mulheres são submetidas a tratamento hormonal, o que pode resultar na produção em série de seres vivos por meio de numerosos embriões congelados e estocados. Segundo esse grupo, as NTRc introduzem uma desestabilização da maternidade, que até então era certa e unívoca, tornando-a agora disseminada e plural. Dentre elas, identificamse àquelas que constroem críticas aos meios publicitários de divulgação das técnicas e à realidade escondida no desenvolvimento das NTRc.

As de segundo tipo contrapõem-se às primeiras, afirmando que ao invés de opor obstáculos aos métodos da procriação artificial, as mulheres deveriam reivindicar seu controle. Para elas, a questão básica é a da liberdade das mulheres. Segundo Oliveira ${ }^{5}$, trata-se de uma posição biofundamentalista, que pode ser classificada como bioliberal; as mulheres só poderiam garantir sua liberdade e a sua autonomia se controlassem essas tecnologias.

Oliveira ${ }^{6}$ afirma ser esta a posição defendida desde 1992 pela Rede Internacional sobre Perspectivas Feministas para a Bioética ( $F A B-$ Feminist Approaches to Bioethics), que congrega mulheres e organizações feministas de 100 países. Essa rede se pauta por uma postura de embate nos meios acadêmicos da bioética e pela luta por uma legislação capaz de coibir os abusos incorporando uma visão de combate à opressão de gênero. Suas posições se fundamentam principalmente, nas vitórias feministas dos anos 70 como: o direito à homossexualidade, à maternidade celibatária, às lutas contra a ideologia normativa do casal e da família.

Essas feministas argumentam que as NTRc excluem certas mulheres e promovem a família nuclear heterossexual como modelo ideal de ambiente para uma criança, enquanto que as do primeiro tipo insistem no aspecto experimental das intervenções praticadas no corpo das mulheres e nos riscos advindos para a sua saúde.

5 Disponível em: <http://culturabrasil.art.br/rib/dpbartigo 1.htm> acesso em: 29 jun..2000 .

6 IDEM. 
Bataille ${ }^{7} \mathrm{em}$ seu estudo sobre as atitudes feministas face à procriação medicalmente assistida, como é chamada na França, identifica uma primeira posição que é desfavorável ao seu uso. Ao conversar com este grupo de mulheres militantes, ele observa que há um sentimento de medo e um receio, diante de todas as intervenções médicas sobre o processo de fecundação. Do mesmo modo que o verificado por Laborie, ele encontra nelas, uma denuncia sobre o desejo de dominação dos processos de fecundação. Elas criticam como os médicos enquanto homens, representantes do masculino, dominam o corpo das mulheres. Colocam em causa o conjunto cultural que favorece a pesquisa, o conhecimento e o progresso, que afasta mais e mais $o$ indivíduo de sua natureza. Para elas o eugenismo é uma das ameaças implícitas dessas práticas, e é resultado de dois elementos de denunciação: os médicos - homens, de um lado e o desenvolvimento científico com seu desejo de regrar a maternidade de outro.

A reprodução assistida é, para essas mulheres, o lugar em que a lógica masculina e científica tende a desapropriá-las de sua capacidade fecundante. Essa posição crítica, segundo Bataille ${ }^{8}$, busca proteger a maternidade das mulheres, e reenvia às correntes feministas que levam à uma separação radical entre o mundo das mulheres e 0 mundo dos homens.

A maternidade valorizada por elas está fora das relações de dominação que combatem e fora dos procedimentos científicos que desnaturalizam esse momento privilegiado na vida de uma mulher. Para esse grupo, só as mulheres têm a capacidade de valorizar seu poder fecundante e de lutar contra a tendência cientificista da humanidade. Ao rejeitar todos os aspectos do conhecimento médico que se insinua entre a mãe e a criança, elas valorizam a expressão natural da maternidade, poder esse existente em sociedades tradicionais.

Nos estudos de Bataille, há um segundo grupo de feministas que percebe 0 conflito entre homens e mulheres com menor violência. A rejeição a essas técnicas médicas se fundamenta em uma crítica do conhecimento científico. A maternidade para elas não é necessariamente uma luta de 
poder entre homens e mulheres. Essas mulheres, que são elas mesmas cientistas, denunciam o desejo de dirigir os princípios da fecundação que têm os homens, mas também as mulheres. É o próprio desejo de regrar esses processos, que eram antes de domínio feminino, e a satisfação aí auferida que é criticada. Tanto homens como mulheres são englobados nessa critica, porque, tanto uns, quanto outros, participam ativamente da ilusão e das possibilidades de regrar os fundamentos da natureza. Elas denunciam radicalmente o duplo fenômeno da vitimização, no qual as mulheres não são meros objetos, embora se submetam a um modelo científico que se permite todos os excessos sobre o seu corpo. Esse modelo critica diretamente a falta de meios permitidos às mulheres que procuram gerir sua esterilidade. Elas constatam o empirismo da ciência e sua notoriedade em termos de prestígio simbólico e, ao mesmo tempo, o desatino dos casais confrontados com o problema da infertilidade. Perde-se, segundo elas, o diálogo entre os casais e estabelece-se o princípio da solução imediata, que os leva a buscar todas as formas de tratamentos tecnológicos, acompanhados de todo desespero humano que isto possa produzir ${ }^{9}$.

O foco de sua posição privilegia as condições deploráveis nas quais se transmite a informação sobre o estado desses conhecimentos. $\mathrm{O}$ casal, segundo elas, não tem tempo para pensar nas dificuldades que encontra em sua existência. Apenas tem a informação de que há uma solução para seu problema doloroso e vai buscá-la. Além do mais, a esterilidade do indivíduo passa a ser a esterilidade do casal. A solução para essas mulheres feministas é apelar para a comunidade científica, exigindo-lhe mais sabedoria e respeito, mais transparência e honestidade.

A denúncia dos desmandos da ciência sublinha o fato de que os homens são, eles também, em graus diversos, vítimas dessa ausência de humanidade dentro da aplicação dos conhecimentos médicos.

Um terceiro grupo recusa o radicalismo e assume um feminismo negociado. Desejam uma atitude ponderada entre lembrar o intenso momento de atividade e de solidariedade que reinava no feminismo, no que tangia as

9 Sobre a justificativa do desespero humano em particular das mulheres, ver FRANKLIN, Marilyn, 1990 e 1995. 
relações entre mulheres e a não-adesão a nenhuma corrente feminista. Elas se situam no limite das reações possíveis e reenviam diretamente a todas as correntes de participação e compreensão da luta feminista. Não colocam em causa a legitimidade do combate feminista. Apenas transgridem as divisões internas e matizam a luta com outra dimensão, que não é o resultado de um não-conhecimento do feminismo ou de uma hesitação, mas o resultado de uma ação estratégica.

Em relação à reprodução assistida, elas se propõem a denunciar pontos precisos, mais do que dar um sentimento geral de aceitação ou recusa. Criticam a ausência de reflexão feminista e constatam que falta maturidade e realismo no desejo de ter filhos das mulheres. Ao invés de criticar as mulheres que se lançam nesses procedimentos e o setor médico que os propõe, elas constatam que o movimento das mulheres não tem levado a fundo à reflexão sobre o tema. Esse grupo aponta uma diferença entre o desejo de gravidez das mulheres e o desejo de ter filhos do casal. Exprime a vontade de não separar as mulheres da dimensão relacional do seu desejo, notadamente da relação com o masculino.

Em princípio, as mulheres deste grupo estão de acordo com a rapidez das descobertas da ciência médica. Para elas, é grotesco colocar em causa o masculino e se mobilizar contra as técnicas empregando esse argumento, sem levar em conta um trabalho real sobre a demanda das mulheres que a elas se submetem. $\mathrm{O}$ aspecto tecnológico não é um problema em si. $\mathrm{O}$ problema também não reside na circulação de informação, mas na ausência de comunicação, e o feminismo tem a vocação de ajudar a comunicação entre os indivíduos.

Segundo Bataille ${ }^{10}$, para esse grupo é ainda inútil se engajar desesperadamente nos princípios de diferenciação entre homens e mulheres, baseados unicamente nos fundamentos biológicos. Elas não se ancoram de maneira definitiva e inelutável nos princípios das diferenças entre homens e mulheres, sobre a solitária base biológica dada e imutável, nem se opõem, nem rejeitam o conhecimento nesse domínio. No aspecto prático, parece que 
as mulheres aceitam correr riscos. Elas valorizam o mundo da experiência, guardam-se de reações defensivas, e fazem-se passar por inconscientes.

No quarto tipo agrupam-se as mulheres que valorizam 0 conhecimento e o progresso. É o grupo constituído por aquelas que vieram das lutas políticas, mulheres que tinham um passado no feminismo igualitário, algumas com reconhecimento dentro da extrema esquerda ou no partido comunista ou ainda dentro do partido socialista. Elas consideram essencial a preservação das relações do casal que tem o desejo de ter filhos, embora não permitam que a discussão sobre o que significam para a mulher seja minimizada.

Para elas, se as técnicas se engajam na solução da dor ou na ultrapassagem dos limites biológicos, isso é um verdadeiro progresso e uma verdadeira libertação. A reflexão que fazem sobre os processos de medicalização da maternidade as incita a pensar que a reprodução assistida pode ser considerada uma expressão do progresso e encorajam as mulheres a mobilizar as tecnologias que permitam melhor controlar sua fecundidade ou a condição de sua gravidez. Entretanto, segundo esse grupo, não há por que fazer dessas técnicas a ponta de lança de novas práticas sociais, embora, uma mulher sozinha, querendo um filho, deverá poder aceder as possibilidades para tê-lo. Por outro lado, recusam-se a ver a medicina se transformar na medicina do desejo. Trata-se de remediar uma demanda lúcida, que é complexa e ambivalente. Elas lembram como as mulheres se beneficiaram do progresso, do conhecimento e da tecnologia. Mas, especialmente, lembram a que ponto os jovens médicos homens foram solidários e às vezes mesmo se engajaram na causa das mulheres. Elas se opõem à barriga de aluguel e denunciam explicitamente a exploração econômica entre as mulheres que deriva dessa prática, principalmente do comércio do útero e de óvulos.

Para um quinto grupo, a denúncia é um debate inútil; segundo elas, se a criança é feita por um homem, dois homens, uma mulher ou duas mulheres, ou sem homem, não importa; o que importa é a sociedade na qual a criança será criada. Elas constatam que as mulheres são ainda hoje em dia submissas à sua biologia, e que as relações sociais são as bases do sistema de filiação que ainda favorece os homens. Elas não reclamam 
de que as crianças sejam feitas por meio de técnicas sofisticadas que substituem a capacidade fecundante das mulheres. Mas refutam caracterizar as mulheres, antes de tudo, pela sua especificidade biológica. Criticam o conteúdo ideológico do desejo de ter crianças e lutam contra a medicina do desejo como redutora da identidade das mulheres. Interditam o corpo médico de ser ele próprio o censor, que decide a validade de uma demanda. São as estruturas sociais onde se apóia o desejo, que são criticadas, e não o desejo em si mesmo.

Essas posições apresentam o quadro de por onde andaram algumas das questões suscitadas pelo contexto pragmático das NTRc. É preciso dizer, porém, que passados alguns anos desde esses e outros estudos, e verificada a complexidade das demandas e das decisões possíveis no campo. Hoje, podem ser identificados novos desafios juntamente à exigência de algumas novas definições que envolvem as práticas sociais. Particularmente, as que dizem respeito às provocações e as experiências advindas de um fundamento tão essencializado, como é o desejo pelo filho do próprio sangue, e a consideração de que uma mulher só é feliz se for mãe, por parte da biomedicina e de muitos setores da sociedade em geral.

$\mathrm{O}$ feminismo tem colocado como centro das discussões os direitos sexuais e reprodutivos, principalmente, no que diz respeito a autonomia, a liberdade de escolha e a ausência de riscos. No Brasil, as discussões sobre a necessidade de uma manifestação legislativa para esse campo, também vêm se configurando e exigindo ponderações. Principalmente, diante dos subterfúgios utilizados por quem pretende legislar, podendo este ato ao mesmo tempo que significa proteção aos dịreitos da mulher invadir absurdamente os mesmos direitos, bem como a sua autonomia. Também porque há um desfocamento evidente dos temas ligados ao contexto das críticas e das denúncias que se originalmente eram criticadas no contexto do tratamento, agora segundo Diniz e Costa (2005), são recortadas por parâmetros morais quando buscadas por casais homossexuais.

As questões apontadas até aqui são aquelas que de certa forma já ganharam visibilidade. Quando se adentra, porém, na experiência vivida por casais verifica-se uma dinâmica que faz interagir abertura para o risco e a construção de desejos que os tornam cada vez mais vulneráveis na busca 
de recursos tecnológicos para a solução do seu sofrimento, fazendo-os até mesmo vivenciarem situações de morte, conforme apresentamos a seguir.

\section{OS PARADOXOS}

Muitos são os problemas enfrentados pelos casais e médic@s durante o processo de tratamento para engravidar. Desde a escolha do modo de medicalizar, o tempo que será investido e o dinheiro necessário, até 0 aparentemente, mais pontual dos conflitos, que começa com o uso da medicação.

$\mathrm{E}$, se por um lado, em situações não incomuns, os casais relatam como estabelecem limites aos procedimentos médicos, especialmente, quando interferem sobre a quantidade de medicação utilizada por eles em cada ciclo, a partir dos sintomas e das queixas das mulheres reveladas pelas reações em seu corpo. De outro, eles também problematizam a responsabilidade do médic@ nas decisões que dizem respeito ao foro íntimo da sua reprodução. Especialmente quando se trata da superovulação e da quantidade de embriões a serem transferidos. Dizem, claramente que, se problemas acontecem por causa da impossibilidade de se saber antes do procedimento, como o corpo irá reagir em relação à medicação, 0 que, em sua avaliação, confirma como tudo isso é ainda experimental, por outro lado, falta uma postura ética e responsável na hora de decidir sobre a quantidade de embriões a serem transferidos.

$\mathrm{O}$ problema sobre o que fazer com o número dos embriões, quando ele é superior a quatro, situação que permitiria a transferência em sua totalidade, segundo a orientação do Conselho Federal de Medicina, embora haja uma tendência mundial de transferir somente dois, constituise em uma decisão que envolve questões éticas e risco de vida para mulheres e crianças.

Essas questões ainda que antigas, nem sempre são levadas a sério antes de começar o tratamento, o que exige, na hora da coleta dos óvulos, uma decisão para a qual os casais não estão preparados. Ou melhor, trata-se de uma decisão de risco, porque, quanto menos embriões são feitos e transferidos menor a chance de sucesso naquele ciclo. Ao mesmo 
tempo, fazer todos os embrióes possibilitados pelos gametas implica em criopreservação, visto que o limite de até quatro embriões para a transferência já é um número bastante elevado, ainda que em muitas situações sejam transferidos bem mais. $\mathrm{E}$, se nesse caso, o resultado não for a nidação de um único embrião, o que nem sempre ocorre, haverá que se administrar uma série de imprevistos, sofrimentos e até mortes, conforme pode-se acompanhar nos relatados que se seguem. Especialmente, se a solução proposta for a redução embrionária que em geral, joga com princípios éticos e religiosos dos envolvidos.

Nidação de três embriões

Ela - Eu fiquei uma cera porque eu achei que eu não fosse conseguir levar a gravidez para frente. Ninguém achava.

Ele - Nem o médico. Ele dizia para mim, vamos tentar, mas é difícil. Ela é muito pequena.

Proposta médica de redução embrionária: o paradoxo para quem havia buscado tanto.

Em relação ao que foi nos proposto, em relação à retirada [...] com mais de 15 dias tinha que fazer ultra-som. Era uma bolinha, só tinha um coraçãozinho batendo. Era só uma bola, parecia um ovo, mas tinha o coração batendo. Então não adianta dizer que não tem vida. Para mim, se eu perdesse nessa fase, naturalmente eu já iria sentir. Eu iria considerar como perda de um filho. Porque eu vi o coração, tinha coração, tinha vida ali dentro. Isso ia ser outro processo, a minha cabeça iria ficar como se tivesse perdido um filho.

Perguntados sobre se sentiam como um aborto, responderam:

Ele - Não só soava como um assassinato. Isso era mais do que o aborto. Eu não ia poder encarar.

Ela - Eu dizia para ele, como é que naquele dia em diante eu iria comprar roupinhas. Montar o quarto, eu não iria mais ter alegria para isso. Nós paramos, os três dias que nós paramos, foram os três piores dias da minha vida. A gente parou completamente. A gente ligava para a mãe e eu dizia, olha, tchau, as crianças estão dando tchau para a mãe. Eu não falava mais neles, nesses dias que eu precisava decidir, minha mãe diz que eu parei 
e eu não olhava mais para minha barriga. Eu não tocava na minha barriga, eu não conversava mais com eles, eu parei, eu simplesmente parei. Aí, quando a gente decidiu. Eu me lembro muito bem, nós viemos do médico, eu não dormi a noite inteira, eu chorei a noite inteira. Aí de manhã eu fui tomar um banho. E eu decidi, eu não vou tirar. Só que eu já tinha decidido, e ele já tinha decidido. Mas os dois não conversávamos, acho que era porque um tinha medo de que o outro quisesse tirar. Eu só chorava e ele ficava na dele. Sempre preocupado, só que ninguém conversava. Aí nesse dia tomando banho eu decidi que não ia tirar. Ai quando nós vimos a doutora entrando na garagem do prédio, ele disse que ele não queria tirar. E que nós iríamos correr o risco, mesmo se nascesse um excepcional. Um aborto seria algo não programado. No nosso caso nós estaríamos programando.

Ele - Era pior do que o aborto, para nós. Para mim isso era um assassinato.

Ela - Para mim o aborto não deixa de ser assassinato.

Ele - Mas nesse caso havia uma diferença, éramos nós que estávamos decidindo. Para mim isso significava bem mais do que um aborto. Existe essa diferença. $\mathrm{O}$ aborto vem de um caso não programado, no nosso caso seria algo programado.

A culpa e a experiência traumática.

Ela - Era desejado já de anos e de repente a gente precisava dizer, vamos tirar um. Qual deles? Hoje estava dizendo para ele, qual deles nós teríamos tirado? Ontem de madrugada estava olhando para eles e pensei nisso. De vez em quando eu penso nisso. Eu digo para mim mesma, qual deles que não teria nascido? Isso ainda me perturba.

Marlene: por que?

Ela - Eu não sei. Muita coisa ainda me perturba.

Marlene: perguntei, isso te perturba, por que você teve que se colocar a possibilidade da escolha?

Ela - Eu acho que sim... A gente olha assim, fica dizendo, mas como é que eu tive coragem.... Embora a gente saiba que qualquer um corre esse risco. Pensar fora é uma coisa, depois que está aqui dentro da gente é outra. O médico pode até te alertar, dizendo, olha, se tiver três ou quatro, você pode ter que tirar, mas depois que está aqui dentro é muito difícil. 
Aqui dentro é diferente, é teu; aí fica bem mais complicado. Antes tu queres tanto que se falam em tirar tudo, dizes tudo bem, tudo bem. Tanto que quando ele ligou eu fiquei tão atarantada que eu disse, não, se for para salvar dois a gente faz, eu vou falar com o (nome). Tem a certeza. Depois, quando desliguei o telefone, me dei conta. E disse, meu Deus, é meu filho, como é que eu vou tirar meu filho. É quem, qual deles?

\section{RISCOS DE VIDA E SAÚDE PARA A MÃE}

...Quando completou a $27^{\mathrm{a}}$ semana, que eu comecei a tomar a injeção, eu chorava. E porque, eu dizia, não agüento mais . E eu não agüentava, porque era muita dor. Os dois meninos estavam de cabeça para baixo, com os pés nas costas. Então quando eles se mexiam eu tinha uma bola aqui, eu tinha outra bola aqui, tinha uma bola nas costas. Eu não tinha posição para dormir, eu dormia sentada, quando eu conseguia dormir. Então eu dizia, eu não agüento mais. Só que ao mesmo tempo eu não queria tirar, porque eu pensava: vou agüentar mais um pouco. Eu achava assim, mais uma semana, se eu conseguir amadurece um pouco mais. Só que, quando chegou no limite, eu fiquei com problemas cardíacos. A doutora me internou, eu fiquei internada mais de vinte dias. Então ela fez um ultra-som e resolveram naquele dia fazer a cesárea. Porque aí eu já vinha perdendo líquido. Foi no dia do aniversário da médica, foi no dia do aniversário do meu pai. Eles nasceram nesse dia turbulento. Agora tem um monte de aniversários.

Ele - No último mês ela foi para maternidade, ficou internada lá. Ela teve uma gravidez complicadíssima, ela não dormiu direito nos últimos sete meses.

Ela - Eu tive complicações cardíacas, respiratórias, eu não sabia se viria tudo bem. Depois passei para o problema da UTI.

O casal assume toda a responsabilidade sobre esta decisão e não se dá conta que houve um a priori que foi desrespeitado em relação ao número de embriões transferidos.

Marlene: Vocês acham que tem algum problema moral ou ético envolvido nesse tipo de procedimento ?

Ele - Acho que tem por parte do médic@em esclarecer tudo que pode vir a acontecer. 
Ela - Só isso eu não sei . Morais ?

Ele - É. Mas no nosso caso eles não nos impuseram nada, eles mostraram os dois lados. Eu queria saber quais eram as porcentagens. Eles não tinham. Então não tinha nem sobre o que pensar.

Marlene - isso implicou numa decisão individual de vocês.

Ele - Individual não..........

Ela - A minha opinião era não tirar; a decisão dele também era para não tirar.

Ele - A decisão era do casal, não era individual.

Marlene - Sim, é nesse sentido que eu usei o termo individual.

Ele - Sim, é isso. Eles nos passaram a bomba, a bomba está aqui, eles nos disseram, e agora o que vocês vão fazer?

Ela - É, nos passaram a bomba. Eu acho que a responsabilidade era nossa mesmo, acho que não era deles. De jeito nenhum, a responsabilidade é nossa. Nós fomos procurar eles por problemas nossos, então a responsabilidade era nossa. São coisas nossas que estavam em jogo. Realmente éramos nós que deveríamos decidir, eles não poderiam chegar e dizer: vamos tirar. Nós e que deveríamos resolver se íamos tirar.

Ele - Em momento algum eles nos disseram: tem que tirar. Então o que ele disse foi, olha se tiver que tirar um, para salvar dois ...

Ela - Mas eu acho que a decisão era nossa mesmo, eles não tinham como decidir. A não ser que fossem quíntuplos, então realmente eles poderiam chegar e dizer: olha, não dá. Tem que tirar, eu tenho certeza que ele diria se fossem. Quatro, eu já li várias reportagem sobre isso.

Ele - E eu nem sei se no final isso ainda seria assim. Eu não sei se fossem quatro, se $o$ casal ainda tiraria. Acho que a gente ainda tentaria o risco. Acho que, bem pensado, a gente ainda passaria o risco de perder os...

Ela - Quatro eu não sei. Sobre isso eu não sei. Essa decisão seria ainda muito complicada.

Ele - Porque as estatísticas ainda jogariam com o pouco que elas têm.

Ela - Inclusive, quando eu fiz o ultra-som, que eu e o (nome), a doutora fomos juntos e ele disse que eram três. Ele disse: não conta para ninguém que são três. Nós não contamos nem para os nossos pais. 
Marlene: Por que?

Ele - Porque na cabeça dele já passou a possibilidade de ter que tirar.

Ela - Claro que nós contaríamos para nossos pais.

Marlene: Vocês acham que é justo que o casal decida sobre isso, ou isso deve ser legislado?

Ele - Eu acho que o casal tem que decidir. Porque, se fosse legislado, provavelmente eles teriam tirado sem que ela nem soubesse.

Ela - Eu acho que deveria ser legislado, abrindo também um termo de compromisso da parte do casal. O casal teria que ter o direito de optar entre fazer ou não. Assumindo um termo de responsabilidade. É a mesma coisa quando uma pessoa faz uma cirurgia em que existe um risco. Quando corre o risco de vida a família não tem que autorizar. Ao meu ver seria a mesma situação.

Ele - Eu acho que neste caso a última palavra é do casal. Porque até os médicos poderiam fazer. Eles podem te levar lá para fazer um exame e tirar. Eles podem dizer que vão tirar o material para ver como estão os fetos e retiram um a partir do momento que tivesse uma legislação. E, por isso, eu acho que a última palavra é do casal.

Ela - É como eu disse, quando tu vais fazer uma cirurgia de risco, a família não tem que assumir um termo de responsabilidade? É a mesma coisa. A legislação diz isso. Se tu és contrária àquilo, então tu vais arcar com todas as responsabilidades. Então deveria ter um termo que tu assinarias arcando com todas as responsabilidades. Como todo e qualquer risco que porventura tu viesses a ter naquela gravidez. E assinar que tu és e que tu não vais tirar e pronto. Não existem casos por aí de pessoas que são contra transfusão sanguínea? Então eu acho que seria a mesma coisa. $\mathrm{E}$ agora também daria o direito para quem quisesse fazer o que achasse melhor. Eu fui à frente, graças a Deus, eu consegui. Mas muitas pessoas não têm como fazer isso. Eles sabem que não tem como por pré-eclampsia. Se já tem um quadro de pré-eclampsia. O médico tinha medo de pré-eclampsia.

É sempre bom lembrar que todo esse relato não existiria se os fatos tivessem sido evitados, simplesmente transferindo menos embriões. Dos três projetos que tramitavam no Congresso Nacional até 1999, um 
deles ${ }^{11}$ propunha a diminuição de quatro embriões para três, na ocasião da transferência, bem como a exclusão de penalidade para a redução embrionária em caso de risco de vida para a mãe. Posteriormente, o projeto do PL1 184/2003, da relatora deputada Perpétua Almeida, apresentado no Senado em junho de 2003, propõe transferência de embriões somente a fresco e em número de até dois embriões. Sobre a redução embrionária, ou ela não é mencionada ou é proibida tanto no projeto PL120/2003, do deputado Roberto Pessoa, de março de 2003, quando no PL2061/2003, do deputado Maninha, de setembro de 2003.

Para o CFM, a redução embrionária é um aborto, o profissional pode ter seu registro cassado caso se comprove a denúncia. Segundo Diniz $^{12}$ : diferente de outros países, que optaram por não delimitar na lei o número de embriões a serem transferidos por ciclo, no Brasil essa vem sendo uma questão fundamental, impossível de ser resolvida senão por meio da imposição de uma lei. Devido à legislação nacional proibitiva em relação ao aborto - a interrupção de gravidez é considerada crime com penalidades previstas em lei, exceto em casos de risco de vida materna e de gravidez resultante de estupro e se executado nos três primeiros meses de gestação -, o tema da transferência embrionária e seu correlato, a redução embrionária, tornaram-se pauta preferencial de discussões.

\section{PROBLEMAS E PRÁTICAS: LEGISLAÇÃO, EMBRIÃO, CRIANÇA E FILHO.}

Segundo Diniz ${ }^{13}$, o problema da redução embrionária esteve presente desde o início do processo normativo brasileiro, mesmo se alguns projetos considerem a possibilidade de redução embrionária, somente em casos em que não há outro jeito de salvar a vida da gestante. Segundo

11 Senado Federal - Projeto de lei do Senado, n. 90, 1999: 23. Autoria: Senador Lúcio Alcântara. Relatoria; Senador Roberto Requião. O relato completo, segundo Diniz (2000), encontra-se nas atas da Comissão de Constituição, Cidadania e Justiça no Senado Federal, Secretaria Geral da Mesa. Serviço de Comissões. Reunião Ordinária da Comissão de Cidadania e Justiça. 12/04/2000.

12 Diniz, 2000, p.14-15.

13 Diniz, 2000. 
ela, a medicalização da redução embrionária foi uma saída eficaz durante os primeiros tempos da medicina reprodutiva no Brasil. Considerava-se a indicação da redução embrionária, e não havia punições para quem a praticasse. Para justificá-la, apelava-se às legislações de outros países, especialmente às recomendações do Warnock Report ${ }^{14}$, nas quais não estava estipulado o limite máximo de embriões a serem transferidos por ciclo e não se deliberava sobre a redução embrionária. Hoje todos os projetos que circulam na Câmara Federal e no Senado partem do princípio da intocabilidade da vida do embrião.

De acordo com Diniz ${ }^{15}$, a gravidez multigemelar e a redução embrionária têm sido analisadas à luz da legislação nacional sobre 0 aborto e não são tratadas como questões básicas de saúde da mulher ou ainda como restrições científicas e técnicas. Trata-se de um silêncio que une os representantes dos interesses da medicina reprodutiva e os das comunidades religiosas, em uma harmonia difícil de ser desfeita, pela dificuldade em se perceber as possíveis diferenças entre eles.

$\mathrm{O}$ resultado disso, segundo a autora, é que não se discute a relação entre o número de embriões a serem transferidos em cada ciclo em cada situação, nem o risco de gravidez múltipla, nem a questão da proibição de redução embrionária e nem as questões que dizem respeito à saúde da mulher, fases interdependentes das técnicas reprodutivas.

A premissa de que o embrião é um filho impede, do ponto de vista social e psicológico, qualquer interrupção de gravidez. Esse sentimento transforma qualquer ato que tente preservar a saúde da mulher em crime. O casal do extenso relato esteve amparado por toda uma rede de orientação e por ponderações da parte dos médicos envolvidos com 0 processo, desde a inseminação até o diagnóstico de trigêmeos. A equipe médica estudava a possibilidade de uma redução embrionária, embora, nesse caso, deixaram a decisão para o casal, que durante muito tempo sofreu a angústia de não saber como proceder, principalmente porque eram contra o que consideravam um aborto.

14 Warnock, Mary. Report of the Committee of Inquiry into Human Fertilisation and Embryology.

Department of Health \& Social Security. July 1984:5

15 Diniz, 2000. 
O marido diz: aí, marcaram uma reunião para conversar, para mostrar como é que era feito. Mas nós não deixamos ter uma reunião, eu liguei para lá e disse: não é preciso fazer uma reunião para nós resolvermos. Nós resolvemos que ou teríamos os três ou não teríamos nenhum. Nós corremos o risco, corremos o risco de perder todos ou de ter todos; preferimos arriscar.

Embora estejamos falando durante todo o tempo em casal, e nesse caso o marido tenha sido extremamente participante, segundo o relato da esposa.

Ela - Eu fiquei sete meses e meio em casa. Eu não podia fazer nada, no início eu ainda conseguia sair para comprar alguma coisinha. Mas muitas coisas ele comprou sozinho, e ele inclusive era superbabão comigo. Quando ele chegava em casa, eu só ouvia barulho de sacolas, ele sempre vinha com um monte de coisas. E ele me ajudou muito, porque um mexendo, todo mundo já diz que é horrível, imagina três. Várias noites, às 3 horas da manhã, ficava ele andando comigo dentro de casa para ver se eles se ajeitavam. Ele sempre esteve muito presente. Ele abriu mão de um monte de coisas para ficar comigo.

É preciso lembrar que foi ele também a marcar uma consulta em reprodução assistida, sem que ela soubesse, porque ela relata que "depois da primeira experiência”, ....

Aí a minha cabeça não funcionou mais. Tanto que eu levei mais dois anos, quase três, para me convencer a ir a Porto Alegre conversar com o médico.

Ele - Convencer não, eu marquei a consulta e só avisei dois dias antes da gente ir.

Ela -É, ele marcou e disse: olha, nós vamos. Me deu uma enxaqueca tão brava, e eu fui com enxaqueca e tudo. Foi tudo muito rápido, quando eu vi eu já estava num processo no qual não havia mais retorno.

Ele - Eu marquei mais para não interferir na parte dela de medo, na parte emocional dela, porque aí ela já começava pensar antes. Eu, no caso, acho que até ela não engravidou naturalmente por bloqueio, ela tinha medo.

Também foi para ele a comunicação médica sobre a transferência de cinco embriões. Ela tinha seis embriões de oito óvulos, um dos embriões parou de crescer antes da transferência. Essas falas dão indícios de uma 
decisão entre homens sobre as mulheres, mesmo que às vezes sejam os homens que marcam as consultas com médicas mulheres. Não está em jogo aqui o sexo do médic@ mas a visão da ciência que é veiculada. De todo modo, é uma decisão sobre o processo reprodutivo de suas esposas que faz pensar nas desigualdades de gênero imbricadas nessas práticas.

Mesmo se, nesse caso, o casal tenha sido envolvido na angústia, e no sofrimento sobre a continuidade da gravidez. Será no corpo da mulher que se desenvolverão as crianças e que também ocorrerão todos os riscos e as situações-limite entre a vida e a morte. As mulheres parecem estar sempre de acordo, mas, ainda assim, esse seu concordar merece uma análise mais profunda sobre o quanto não estariam apenas atendendo a uma demanda configurada no casamento com sua função na relação social de fazer filhos. $\mathrm{Ou}$, o quanto elas estariam atendendo a demandas psíquicas que não são suas, mas dos seus pais, dos amigos, do marido, do conjunto de relações que as engendram, ou o quanto a própria infertilidade é sintoma de uma negação a maternidade.

O casal em questão justificava a sua decisão, no ato da entrevista, olhando para as crianças e dizendo que se perguntavam todos os dias qual delas teriam "matado". Agora, diante das crianças, é impossível livrar-se da culpa, pelo fato de terem ventilado a possibilidade de tirar um dos embriões, mesmo se independente de sua vontade. A redução era apresentada pelos médicos, envolvidos no acompanhamento desse desfecho, como uma necessidade, para não correr o risco de perder todos os embriões, ou até mesmo de ocorrer a morte da mãe. O que, nesse caso, só não aconteceu porque esta mulher estava amparada, o tempo inteiro, pela cunhada que é médica e obteve acesso rápido ao hospital e à UTI nas situações em que apresentou paradas cardíacas e respiratórias.

Considerar a vida humana sagrada desde a sua concepção impossibilita discutir mais amplamente as questões que dizem respeito aos muitos riscos que as mulheres estão correndo, principalmente, quando se trata dessas situações extremas, geradas no interior dos processos de reprodução assistida.

E substituir embrião por criança, ou o interesse da criança colocado na realidade embrião, também cria situações-limites em relação aos 
riscos à mãe. É justo que os pais submetam crianças a situações tão graves? A redução embrionária não seria uma questão de bom senso e de responsabilidade também para com a vida das crianças, diante do risco extremo de morte a que elas foram colocadas, ao longo do processo de gestação e posteriormente ao seu nascimento? Ou melhor, é lícito deixar que a transferência embrionária continue ocorrendo sobre os critérios da busca de gemelaridade, como foi o caso, ou de sucesso, como é na maioria das práticas? O depoimento a seguir sobre o que ocorreu com as crianças, revela uma situação que poderia ter sido completamente evitada se a transferência de embriões tivesse sido menor. Isso seria o desejável, ou com uma decisão sobre a redução embrionária, embora, como conseqüência já de um processo de medicalização do excesso de nidação. Entenda-se que não estamos fazendo apologia a redução embrionária, mas, uma vez que são transferidos tantos embriões, essa opção está entre outras possíveis, e, precisa ser considerada pelos envolvidos.

Problemas com as crianças.

Ele - As crianças ficaram 25 dias na UTI. As crianças nasceram com 7 meses e meio. Esse primeiro aí do colchão nasceu com 1,230 kg, não, um 1,280 ; outro com 1,630 e 1,360, ela. Além disso, ela deu azar que no primeiro dia em que eu fui levá-la na UTI para ela conhecer as crianças, eles não deixam a gente entrar junto. E ela foi sozinha. E o... do meio fez a parada respiratória na frente dela. Na hora, então, ele teve que ser entubado. Ele nasceu maior, mas ele teve que ser entubado, ele teve uma série de problemas. Ele pegou uma bactéria, voltou; ele incomodou bastante.

Ela - Os outros dois não, eles só ficaram para ganhar peso. Ele, pelo peso dele, não foi para incubadora, quando cheguei, ele estava no bercinho. Aí eu fui direto nele e comecei a conversar com ele e ele parou. Para mim foi horrível. Ele simplesmente olhou para mim e parou, ficou com o olho aberto, parado. Aí começou alarmezinho, todo o mundo correu. As pessoas disseram: não se preocupe, que é assim mesmo. Não te preocupa que foi só uma apnéia, me diziam.Eu chorava desesperada, tinha toda essa ansiedade, esse medo, a gente não sabia se ia dar certo ou não. Em agosto, eu comecei com contração; num domingo, $2 \mathrm{~h}$ da manhã, nós fomos para a maternidade. Eu e ele e a irmã 
dele, eu não sabia se eu ficava lá ou não. Felizmente deu tudo certo, eu voltei para casa. Mas eu fiquei com aquele medo sempre. Eu e ele às vezes chamávamos a irmã dele (médica)..., lá vinha ela. Então tudo era bem ou de modo complicado. E até chegar na $28^{\mathrm{a}}$ semana, quando eu ia começar a tomar a injeção para amadurecer o pulmão deles, para eles terem chance de ir à frente também. Se não, eles nasceram com sete meses e meio também, contrariando todas as expectativas, porque eles achavam que eu não iria segurar.

Outra situação-limite que acompanhei nos últimos tempos ${ }^{16}$, ela com 26 anos, ele com 28 , já faziam tratamento para engravidar há algum tempo, quando resolveram fazer reprodução assistida via fertilização in vitro, na verdade quando estavam decidindo, eles me procuraram para conversar. Situação que é sempre delicada, o que me impede aqui de entrar em maiores detalhes. Mas, o fato é que decidiram, fazer fertilização, mesmo com todas as orientações sobre outras possibilidades e conselhos de casais que já haviam realizado ICSI. Soube, posteriormente, que estavam grávidos de três bebês. Três meninas, contrariando as expectativas da família que queria meninos. A gravidez foi levada até o sexto mês sem grandes problemas, mas, a partir daí, a médica recomendou que a mãe fizesse repouso absoluto porque apresentava contrações e dilatação. Diante da insistência da mãe em voltar para casa, a médica não esclareceu a necessidade de ficar no hospital, o que o casal passou a considerar um erro posteriormente. Os bebês nasceram prematuros, vindo a falecer uma das crianças, uma semana após o nascimento; todas elas foram submetidas a dias de internação e de UTI neonatal. A mãe ficou se deslocando para o hospital que estava a $80 \mathrm{Km}$ de sua casa, e o pai em alto grau de angústia e stress acompanhava quando podia. A situação era limite, todas as crianças estavam com risco de vida. A mãe e o pai, e a cidade inteira estava na torcida sobre o resultado desse parto, embora, seja segredo de todos, a forma como os bebês foram concebidos.

Conversei com o casal algumas vezes, e a maior preocupação da mãe era: "será que meus filhos terão problemas no futuro com isso tudo?"

16 Entrevista realizada em julho de 2004, casal acompanhado sempre que posso. 
Em um dia de angústia, durante uma conversa o pai disse: "se a gente soubesse que isso iria acontecer, não teria transferido tudo, mas a gente queria um filho. A médica não orientou”.

Em relação ao fato de a mãe não ter permanecido no hospital, o casal avalia posteriormente, como o início de sucessivos erros médicos.

Alison - [...] É essa foi outra falha da médica. Foi outra falha grandíssima porque assim, oh. Ela tem experiência, ela convive com isso no dia-a-dia. A Aline já estava com estas contrações. Então ela queria internar a Aline, mas a Aline não queria ficar lá.

Aline - Era tão longe [...], tu sabes, ficar internada não é como na casa da gente.

Alison - Só que assim, ela não fez uma pressão, oh tens que ficar aqui porque estás correndo um risco. Ela não chegou a fazer um pouco de pressão. Ela não esclarece, ela não diz. Porque se ela dissesse: olha Aline, tens que ficar aqui. Ela é bem querida, tem jeitinho atende super bem, mas é insegura para decidir. Ela fica não sei....

Aline - É claro que ia querer ficar na minha casa. Quem é que quer ficar no hospital?!

Alison - Mas ela precisava considerar que tu tinhas que fazer 80 quilômetros. Eram três bebês.

Aline - $\mathrm{O}$ que eu sentia nela era muita tranqüilidade. Com essa gravidez de trigêmeos. Ela passava isso pra gente. Ela previa mais ou menos quando eu ia ganhar [...]; ela dizia que eu ganhar em março. E dizia que eu tinha que me cuidar até janeiro, e que depois de janeiro o que acontecesse não daria mais tanto trabalho. Mas deu o primeiro de janeiro eu ganhei. $\mathrm{E}$ o trabalho? Deu pouco trabalho? Um trabalho que ninguém esperava.

Alison - Não é trabalho isso [...] é o que a gente sofreu ai. Meu eu ainda, tem dias que ainda a gente tá bem. Outros, outros [...] e chora.

No presente como no relato anterior, apresenta-se muita culpa. Quando perguntei sobre se sentiam algum tipo de culpa pelo que aconteceu, Aline respondeu imediatamente: "A sim. Eu me culpei bastante". Alison seguiu dizendo: “Mas, tudo isso, Aline, não foi um erro nosso. É claro a gente tem culpa em parte. Mas a maior culpa vem da médica. Ela não podia ter feito isso. 
Quando perguntei se haviam falado com a médica sobre o ocorrido, Alison diz: "Não adianta, isso foi uma coisa que passou, só se for para evitar que faça com os outros.

E Aline segue: "Mas é impossível ela não saber disso, ela deve se tocar disso; será que ela se toca disso?

Em alguns momentos da entrevista, coloca-se a discussão sobre 0 natural e 0 artificial do processo. De um lado porque fazer filhos dentro da relação sexual é considerado "mais natural". De outro, porque no caso deste casal, por causa da morte de uma das meninas, eles sentem como se tivessem ferido a ordem natural das coisas.

Alison diz:

Não é uma coisa natural; é uma coisa programada. É uma coisa muito artificial. É muito artificial. Se bem que é como eu já disse pra ti, se a gente tivesse que fazer de novo a gente faria. Porque um filho para um casal é uma coisa inexplicável. $O$ benefício que traz para o casal. Mas é muito medicamento; é medicamento muito pesado.

Perguntei se filho concebido através da relação sexual poderia ser considerado natural?

A que Alison respondeu:" É, o processo é bem mais natural. Uma coisa de Deus, assim. Acrescentei: e agora tu achas que tu feristes o plano dele? Uma norma de Deus?

Ele responde: "É uma coisa assim, uma coisa que não é o certo da natureza, uma coisa normal." E acrescenta: "Talvez eu esteja falando isso porque a gente perdeu um neném, talvez se a gente não tivesse perdido o neném eu não diria isso" .

Perguntei: Mas tu pensas que a perda do neném é castigo divino?

Alison - "Eu não sei, hoje em dia a gente não tem certeza de nada. Ninguém dá uma explicação pra nada hoje em dia".

Aline diz: "Mas às vezes precisa fazer repouso, eu fiz repouso".

Ele volta ao tema da responsabilidade médica. "Só que o que ela passava para a Aline era bem natural, nada artificial. Ela recomendava o repouso".

Aline - Decerto ela achava que eu ia trabalhar. Talvez pensasse que eu ia abastecer, limpar carro. Depois que eu engravidei, não fiz nunca mais nada disso. Eu ficava no caixa, sentadinha. 
Alison - Ela ia na casa da mãe tomava o café com horários bem controlados.

Aline - De repente, se eu tivesse feito um pouco mais de repouso, talvez eu tivesse conseguido sustentar mais um mês. É isso que eu fico me culpando às vezes. Parece que eu não fiz repouso suficiente. Mas isso era algo normal da natureza. Eu encarei com naturalidade. Ela falava com tranqüilidade, com naturalidade sobre o repouso. Ela nunca nos pressionou para fazer repouso.

Alison - Tá assumindo uma culpa que nem é nossa.

Aline - Ela poderia ter dito para ficar no hospital.

Alison - Ela tem uma carga horária muito puxada. É assim, oh a gente chegava lá. Ela não tinha tempo. Ela não almoçava, chegava o pessoal da tarde e ela atendia a uma hora. A gente chegava às 10 horas; ia ser atendido a 1 hora. Ela não almoçava. Estava chegando o pessoal da tarde, e nós estávamos lá e já estava chegando o pessoal da tarde. Ai que tá; ela não tinha tempo para dar uma atenção pra gente. Pra fazer a gente ver como é o negócio, o negócio todo. Ela quer abraçar tudo de uma vez só. A fama né. Ela falou que a clínica dela era a que mais dava certo, né Aline. Que o maior índice de sucesso era o dela. Ela mexe com um monte de coisas, mexe com o nosso emocional, com hospital, com UTI, com neonatal, leito superlotado.

Um ponto bastante sofrido foi a referência constante sobre a bebê que havia morrido. Ela já tinha nome; eles se referiam a ela, sempre pelo nome, como alguém que havia partido antes da hora, e como um vazio deixado na relação com as duas bebês que sobreviveram.

Quando perguntei: E quando vocês olham para as duas vocês lembram da outra. Ele respondeu com a voz entrecortada "quase sempre", comentário que foi seguido pelo choro.

Tentei quebrar a situação e disse: isso te machuca? Ele chora e diz: bastante (silêncio), e acrescenta: “ eu a visito no cemitério”. Aline acrescenta: eu não vou.

Ele pondera: "Nesse pedaço a Aline é mais forte. Daí assim oh. É difícil, e eu sempre choro" .

Aline completa: "Talvez com o tempo". 
Eu pergunto e como é conviver com a vida e com a morte?

Alison diz: "A gente fica revoltado ao mesmo tempo; vem a alegria total. Mas a médica jamais poderia ter colocado cinco embriões. Jamais. A gente também não deve falar muito, Marlene, porque assim oh.....porque graças a Deus a gente tem as duas. A gente tem as duas.

Ponderei que talvez poderia ter havido outras escolhas. Perguntei se a médica os tinha consultado sobre a transferência dos embriões. Quando ela resolveu pôr os cinco embriões o que ela disse? Ela perguntou?

Aline respondeu - "Ela disse que achava melhor colocar todos".

Perguntei: Ela disse logo assim, é melhor colocar todos?

Aline responde: "Ela disse que não eram bons".

Perguntei sobre quem deveria decidir em relação a quantidade de embriões a serem transferidos. Aline respondeu imediatamente: "O médico".

Ponderei: "Mas ela decidiu” .

Aline disse: "Ela decidiu errado, ela colocou cinco. Ela tinha que colocar dois, no máximo."

Alison completa: Ela jamais deveria ter posto cinco. Ela devia por dois. Insisto: Ela deveria ter perguntado?

Alison responde: Ela até perguntou [...]; ela queria colocar quatro. Mas, aí, ela disse que os cinco estavam prontos e que ia por os cinco. Aline lembra: "ela disse que não tinham qualidade ${ }^{17}$.

E segue dizendo: "Alison, mas olha, antes de qualquer coisa a gente tinha que ter feito essa conversa. Antes de iniciar o tratamento. Antes de tudo. Se a gente tivesse tido essa conversa que a gente teve hoje. Jamais ia por cinco".

Alison retruca: "Com a carga horária que ela tem. Ela não tem condições nunca de ter uma conversa. É que com o ritmo que ela tem é impossível dispor de meia hora para explicar. Ela atende telefone, atende mil pessoas ${ }^{18}$.

O discurso sobre a qualidade do material é utilizado pelos médicos sempre, e é imprescindível tanto para manter as expectativas de sucesso quanto para preparar o casal, quando o médico acha que não dará certo. Fala-se no número de folículos, na qualidade dos óvulos e espermatozóides, na qualidade dos embriões. Alerta-se para o fato de que esses elementos 
são fundamentais para se obter um bebê. Esse comportamento, na maioria dos casos, impede que o casal se rebele contra outros fatores, como a tecnologia, o medicamento, as condições da clínica e do laboratório, o conhecimento médico, que jogam igualmente papel fundamental em relação aos resultados, se positivos, ou não ${ }^{19}$.

Nesse caso ganha outra ordem de conteúdo, possibilita uma decisão sobre transferência de embriões em maior número.

Em relação a este vivido em geral (são muitas as questões aqui), 0 marido parece estar sempre mais lúcido sobre os critérios do agir médico e assume durante a entrevista uma atitude de analítica e orientativa em relação a sua companheira.

Ele diz: "É que é assim, Aline, ela quer sucesso em tudo o que ela faz. Ela vai estar sempre do lado certo. Ela quer garantir sucesso em tudo o que ela faz. E para garantir sucesso ela usa até a última, até a última. Ela usa todos os cartuchos que ela tem. Entendeu. Tu vês ela colocou cinco embriões".

Volta-se para mim e diz:" Pela idade da Aline, pelo organismo dela".

Se volta para Aline e diz: "Estava tudo perfeito, né Aline.

E segue: "Pelo que ela tinha, ela conhece o organismo das pessoas, ela é uma médica. Sei lá, ela não precisava ter colocado cinco. Se a Aline tivesse 35 ou 40 anos. Se uma pessoa está perto dessa idade, aí tudo bem colocar os cinco. Também, não sei também. Mas no caso da Aline a taxa de sucesso era talvez até então. Eu sempre dizia para Aline que vai dar certo, não tinha porque não dar. Eu dizia, tu és uma pessoa nova, uma pessoa que não tem problemas de saúde. Mas, também, não deu outra né $[\ldots]$ e foi $[\ldots]$.

17 É interessante observar que também em entrevistas anteriores, essa fala sobre o embrião, que não é bom, ou o óvulo que não tem boa qualidade, ou o espermatozóide que não funciona, apareceu o tempo todo. Nunca é responsabilidade da equipe médica, ou do biólogo, ou do material utilizado, ou da tecnologia; nunca são os meios de cultura, ou a infra-estrutura da clinica. Jamais se discute os fatores externos, as células dos corpos;óvulo e espermatozóide, ou externos ao embrião (TAMANINI, 2003).

18 Há relatos dos casais sobre o agir médico que vai desde o atender telefones, fazer compras até de carros durante a consulta, dentre outras situações, em outras entrevistas, discussão que se encontra em TAMANINI, 2003.

19 TAMANINI, 2004. 
Seguindo o relato das complicações que viveram, Aline diz: "Eu tive complicação. Eu tive hiperestimulação. Com a medicação eu tive ascite depois da transferência".

Alison completa: "Mas olha ela não conversou nada. Nada sobre 0 que estamos falando agora. Nada. ...A gente não foi nada informado. Sobre nada. Nunca teve esse diálogo".

Perceba-se que o casal está elaborando sua compreensão diante do ocorrido na situação de entrevista

Perguntados sobre o que teriam feito caso tivessem sido informados ele responde: "Seria importante porque a gente sabia que algum risco sempre se corre porque não é uma coisa natural. É uma coisa artificial. Desde o medicamento, a fertilização dos óvulos, a fecundação ali, etc. Só que isso deve ser feito com dois embriões. Jamais com cinco".

Ela - Eu nada sabia sobre a hiperestimulação.

Ele - Ela podia ter diminuído a dosagem de remédio, já que a Aline é uma pessoa nova. Não dá tanto remédio porque a Aline tinha caixas de remédios; ela enchia.

O fato acima dá conta de relatar a experiência prática dos casais, e coloca a questão de que é preciso considerar a rotina tão intensa de cuidados, exigida pelos bebês, e pela manutenção do segredo sobre sua concepção, 0 que torna muito difícil administrar o cotidiano após o nascimento de tantos bebês de uma vez. Nesse caso, marcados pela morte de um deles. Como conciliar trabalho, recursos econômicos e atenção prioritária aos bebês. Além disso, existe a questão do interesse da criança que têm também suas consequiências práticas, jurídicas e institucionais.

Nesse caso parece tratar-se da necessidade de focar com maior rigor os exageros quanto ao número de embriões transferidos, uma vez que uma decisão posterior, seja para reduzir ou para administrar culpas, é bem mais exigente em termos de mediações sociais, familiares, psicológicas, emocionais e afetivas, para citar algumas. Sem pensar nas questões relativas ao relacionamento do casal pós-nascimento e ao sustento de tantos filhos de uma só vez.

Estou de acordo de que há um crescente consenso no sentido de que é preciso regulamentar as tecnologias reprodutivas no Brasil, tanto no que 
diz respeito ao acesso, quanto ao seu uso profissional. No entanto, além da incorporação dos debates sobre pesquisas científicas com embriões e da alocação de recursos para o exercício da reprodução assistida nos serviços públicos, conforme já apontando por Diniz ${ }^{20}$. Há necessidade de regrar as condutas que passam por dentro dessas práticas nos consultórios e que não dizem respeito a um quadro legal coletivo, mas que se configuram de um jeito nas clínicas privadas e de outro nos serviços do SUS, embora em ambos possam comprometer a integridade e a dignidade das decisões. Condutas que são envoltas em subjetividades e iguais periculosidades, mesmo que sobre elas seja difícil legislar, mas, se possível fosse, pouco ou nada adiantaria, porque ainda passam pelos entendimentos da subjetividade médica sobre a vida. Muitas são as falas que fazem pensar sobre isso, e, talvez só a publicização e a discussão coletiva permita uma atenção maior por parte da sociedade em relação ao que está acontecendo.

Deste modo, nos limites de um artigo, queremos pontuar que o uso das NTRc, em razão do desejo de ter filho pode ser uma falácia que opera a busca de identidade e sentido, por parte do sujeito feminino e para o desenvolvimento da pesquisa e da experimentação científico-tecnológica, que não responde ao desejo de nenhuma mulher. É lícito perguntar-se sobre o destino psíquico de uma criança gerada em tais condições? O filho, nesse caso, não seria apenas um capital narcísico, e a supervalorização genética e genealógica não estaria apenas colaborando para isso?

Quando se apresentam os aspectos ligados aos riscos, está-se, ao mesmo tempo, diante do desafio de se colocar dentro e fora da crítica feminista. Dentro, para se analisar o que significam os interesses políticos, mercadológicos, a relação custo-benefício, as condições de desinformação dos casais que procuram essas tecnologias, e do próprio desconhecimento médico sobre essas formas de tratar. Tomar em conta o dever da concepção que está sendo reforçado no interior dos processos da busca pela paternidade, através do filho biológico/genético, e da maternidade essencializada, faz pensar o modo como os seres humanos estão escolhendo viver. A ampliação do consumo dessas técnicas se transforma rapidamente

20 DINIZ, 2000. 
na única solução para a esterilidade, tornando-se socialmente impositivas, apesar dos seus altos custos, de seus impactos sobre a saúde e de uma taxa de êxitos proporcionalmente limitada.

Estar fora da critica feminista permite pensar os novos significados dos riscos, construídos pelos envolvidos, aliados, conforme afirmam Douglas e Wildavsky ${ }^{21}$, ao fato de que as escolhas das nossas instituições e de como queremos viver, levam a medos comuns, assim como a um acordo implícito sobre o que não devemos temer. No caso das novas tecnologias reprodutivas, isso parece ser um dos aspecto importante, associado ao substrato cultural de gênero que ainda valoriza em demasia o papel da maternidade como vínculo de reconhecimento social, com todas as espécies de mitos que nele podem estar embutidos.

Logo, as escolhas estão "empapadas" pelo processo sociocultural que, segundo Douglas e Wildavsky ${ }^{22}$, dificilmente tem uma relação direta com o caráter objetivo dos riscos. Os interesses das instituições médico-hospitalares, dos laboratórios e das clínicas, são apontados como espaços de vinculação com a nova construção da engenharia genética e são ligados à lógica do mercado, do consumo e da transferência biotecnológica. A associação de todos os atos reprodutivos permite também visualizar os aspectos que se constituem em novidades radicais no modo de conhecer e atuar contemporâneos e que, de alguma maneira, indicam a necessidade de revisar os valores fundantes da ação humana, como eles se coadunam, rearticulando o processo sociocultural ao processo sociotécnico, e como se interagem entre $\mathrm{si}^{23}$. No limite, as reais possibilidades da vida humana estariam sendo transformadas, para que se possa até mesmo gerar um mundo de criaturas híbridas, como descrito por Haraway ${ }^{24}$.

O desafio que persiste para a consolidação conceitual e prática dos direitos reprodutivos estabelece-se no questionamento do forte legado dessa

21 DOUGLAS; WILDAVSKY apud GUIVANT 1998.

22 DOUGLAS; WILDAVSKY, 1983.

23 ROTÂNIA, 1999.

24 HARAWAY, 1995. 
base (individualista e liberal) da modernidade, que iguala, ontologicamente, o dizer não à maternidade imposta, com o dizer sim à maternidade tecnológica, a naturalização das diferenças sociais e a remodelação cultural da natureza ${ }^{25}$.

Essa paradoxal situação afirma 0 individualismo e 0 conservadorismo no contexto das altas tecnologias. O retorno à "ficção biológica" e à procriação pode reforçar, em certa medida, de uma parte, as tendências etnicistas, inclusas as racistas, por causa das discriminações; de outra parte, o individualismo, próprio das sociedades industrializadas, o que leva em si, oculta a reivindicação da realização de velhos fantasmas, tanto por parte dos casais que demandam um filho biológico, como por parte dos cientistas e médicos que baseiam sua ação, na ética querer do casal e na ajuda à natureza ${ }^{26}$, em condições desiguais de gênero.

Portanto, não é suficiente a crítica à sociedade de risco como uma sociedade auto-crítica. As práticas de denúncias do risco trazem um conflito fundamental que a caracteriza e que se coloca no bojo do velho ordenamento industrial, como apropriação da natureza. Tal conflito, segundo Beck ${ }^{27}$, se refere as contradições ideológicas, culturais, econômicas e políticas, agrupadas e perfiladas, umas frente às outras, em torno da dicotomia "seguro inseguro". A questão muito bem colocada pelo autor é: ou se combate a imprevisibilidade e a desordem produzida pelo modelo da racionalidade teleológica com os procedimentos da velha sociedade industrial (más técnicas, mercados, Estado), ou se começa aqui uma maneira de pensar e atuar distinta, que aceita a ambivalência com todas as conseqüências de grande alcance para o conjunto e domínios da ação social.

Essa perspectiva só é possível, segundo Beck, quando se abandona a ótica da ordem, a visão unidimensional da racionalização ocidental e passa-se a se preocupar com a própria reflexão científica, colocando 
no centro do social o ambíguo, o incerto, o contingente e o contextual, assumindo uma postura reflexiva. O mesmo em certa medida, nos sugere Dhavernas $^{28}$, ao refletir sobre as dificuldades que tem em romper com antigas concepções e aproveitar das "novas realidades" para eliminar de uma vez todas as noções de continuidade. A perenidade existente dentro dos modelos espontâneos é sentida como necessária, cuja evidência, no que se refere à maternidade, não é desprezível no pensamento patriarcal. Lugar da fala de onde o feminino é associado à desordem e ao caos, e o maternal representa a permanência e a imutabilidade. Ambos coexistem, por sua vez, dentro da essência atribuída às mulheres, e à medida que nos posicionamos contra outras possibilidades, poderíamos, segundo ela, estar mantendo todas as dicotomias, com suas essencializações sobre o corpo.

O problema é que ao meu ver, mesmo que pensemos uma série de escolhas colocadas a disposição para os indivíduos; mesmo que a resposta, apropriada ou não, seja construída a partir do horizonte compartilhado da realidade; e ainda que consideremos os intercâmbios com pessoas e objetos no contexto da prática diária, como condição necessária do que pode ser dito, e dos significados implicados na consciência prática ${ }^{29}$, ainda assim, apropriar-se da realidade externa é um caminho de realidade mediada, onde o corpo encontra-se em risco constante, inclusive nos ambientes mais familiares.

Desse modo, somente os sistemas de confiança sem as mediações legais não respondem às necessidades subjetivas das mulheres e, embora organizem grandes áreas do ambiente material e social, não é possível para a maioria delas a oportunidade de escolha e a certeza do funcionamento apropriado. Além disso, há que se ter em conta que os direitos têm sido interpretados como atributos dos indivíduos, faltando, por vezes, as responsabilidades recíprocas para uma sociedade justa. Isto implica também em segurança, o que não significa apenas estar livre de doenças, mas de abusos, dentre eles, a ausência de coação. 
Portanto, nos ataques politicamente engajados feitos a vários empirismos, reducionismos ou outras versões da autoridade científica, a questão não deveria ser relativismo e sim posiçãa ${ }^{30}$. Segundo Haraway, conhecimentos locais também têm de estar em tensão com as estruturações produtivas que obrigam traduções e trocas desiguais, materiais e semióticas, e obrigam a encarar o lugar particular como um mapa de tensões, ressonâncias, transformações, resistências e cumplicidades. Buscar, portanto, as interfaces, as metáforas e as maneiras de entendimento e de intervenção nos padrões de objetivação do mundo. No interior desse processo encontra-se modos de apreciar simultaneamente ambos o aspecto concreto, "real", e o de simiose e produção no que chamamos de conhecimento científico. Desse ponto de vista, segundo Haraway, é preciso assumir uma postura a favor de políticas e epistemologias de alocação, posicionamento e situação, nas quais parcialidade e não universalidade é condição para ser ouvido nas propostas a favor do conhecimento racional. Esse conhecimento racional feminista não tem a pretensão do descompromisso, de pertencer a todos lugares e, portanto, a nenhum, de estar livre da interpretação, da representação, de ser inteiramente autocontido ou inteiramente formidável.

O conhecimento racional é um processo de interpretação crítica contínuo entre "campos" de intérpretes e decodificadores; é uma conversa sensível ao poder. Faz-se necessária uma postura de decodificação e transcodificação, mais tradição e crítica. O único modo de encontrar uma visão mais ampla é estar em algum lugar em particular. Saberes localizados requerem que o objeto do conhecimento seja visto como um ator e agente, não como uma tela, um terreno ou um recurso, e, finalmente, nunca como um escravo do senhor que encerra a dialética apenas na sua agência e em sua autoridade de conhecimento objetivo. Nesse sentido, para além da confiança em sistemas peritos, conforme proposto por Giddens, coloca-se o problema de quem os controla. A ciência nos últimos anos vê-se obrigada a ampliar o grau

30 HARAWAY, 1995. 
de diálogo com diferentes setores da sociedade, além de aumentar o número de rachaduras internas, demonstrando suas próprias contradições. A noção de riscos aceitáveis, riscos reduzidos a um ponto satisfatório pelo sistema perito, na prática não pode garantir que todas as mulheres sairão ilesas das experiências. Há que se tomar, portanto, uma postura de maior amadurecimento do significado social e ético dessas intervenções e sobre suas possibilidades de mudar de modo irremediável a singularidade humana (dos homens e mulheres das gerações futuras).

\section{REFERÊNCIAS}

ÁVILA, Maria Betânia. Direitos reprodutivos: uma invenção das mulheres reconhecendo a cidadania. Mandrágora: direitos reprodutivos, religião e ética. São Bernardo do Campo, ano 4, n.4, p. $11-26,1997$.

BATAILLE, Philippe. La dimension ethique des mouvements d'action culturelle: réactions de femmes féministes au thème de la fécondation assistée. In: Information sur les sciences sociales . Londres: SAGE, Newbury Park et New Delhi. n. 29, v.3, 1990. p. 583- 617.

BECK, Ulrich. On the logic of weatlh distribution and risk distribution. In: Theory, culture \& society. Mark Ritter translated Towards a new modernity. London/Thousand Oaks/New Delhi: Sage publications, 1996. p. $19-50$.

CHATEL, Marie-Magdeleine. Malaise dans la procréations: Les femmes et la médecine de l'enfantement. Paris: Albin Michel, 1998.

DHAVERNAS, Marie-Josèphe Levy. Essentialisme et biologisme dans les nouveaux modes de procréation. In: HURTIG, Marie-Claude; KAIL, Michèle; ROUCH, Hélène. Sexe biologique et sexe social. Paris: CNRS, 2002. p. 270-285. 
- Reproduction médicalisée, temps et différence. Cahiers du Genre. Paris: L'Harmattan, n.25, p. 167-188, 1999.

DINIZ, Débora. Tecnologias Reprodutivas, Ética e Gênero: o debate legislativo brasileiro. Série Anis, n.15, Brasília, 2000.

DINIZ, Débora; BUGLIONE, Samantha. (Edas.) Quem pode ter acesso às tecnologias reprodutivas - Diferentes perspectivas do direito brasileiro. Brasília: Letras Livres, 2002a.

DINIZ, Débora; GUILHEM, Dirce. 0 que é bioética? São Paulo: Brasiliense, 2002b.

DINIZ, Débora; COSTA, Rosely Gomes. Infertilidade e infecundidade: acesso às novas tecnologias conceptivas. Série Anis, n.34, Brasília: LetrasLivres, p. 1-12, jan., 2005.

DOUGLAS, Mary; WILDAVISKY, Aaron. Risk and culture: an essay on the selection of techonology an environmental. Berkeley/Los Angeles/ London: University of California Press, 1983.

FAURE- PRAGIER, Sylvie. En finir avec la stérilité psychogène: Pour une théorie de l'inconception. Cahiers de Maternologie. Revue de la Maternité Pyschique. Bébé 2000 les Révolutions de la Parenté. Paris, n. 11, p. 55-61, juil.- déc., 1998.

Les bébes de l'inconscient: les psychanalyste face aux stérilités féminines Aujourd'Hui. Paris: PUF, 1999.

FRANKLIN, Marilyn. Deconstructing 'desperateness': the social construction of infertility in popular representations of new reproductive techonologies". In: MCNEIL, Maureen; VARGOE, Ian; YEARLEY, Steven. The new reproductive technologies. London: Macmillan Press, 1990. cap. 8. 
FRANKLIN, Marilyn. Posmodern Procreation: A Cultural Account of Assisted Reproduction. In: GINSBURG, F. D.; RAPP, R. Conceiving the new world order: the global politics of reproduction. London: University of California Press, 1995. p. 323-345.

. Deconstructing 'desperateness': the social construction of infertility in popular representations of new reproductive techonologies. In: MCNEIL, M.; VARGOE, I.; YEARLEY, S. The new reproductive technologies. London: The Macmillan Press, 1990. cap. 8.

GIDDENS, Anthony; BAUMAN, Zygmunt; BECK, Ulrich; LUHMANN, Nicolas. Las consecuencias perversas de la modernidade. Coleção dirigida por Josetxo Beriain. Tradução de Celso Sánchez Capdequí, Revisão técnica de Josetxo Beriain. Barcelona: Anthropos, 1996.

GIDDENS, Anthony. Modernidade e auto-identidade. In: Modernity and sel-identity. Londres: Polity Press, 1991. cap. I, p. $1-9,36-37,126-137$.

GUIVANT, Julia. A trajetória das análises de risco: da periferia ao centro da teoria social. BIB, ANPOCS , n. 42, p. 3- 8, 2º semestre de 1998.

HARAWAY, Donna. Saberes localizados: a questão da ciência para o feminismo e o privilégio da perspectiva parcial. Cadernos Pagu. Campinas: Unicamp, Núcleo de Estudos de Gênero, v.5, 1995. p. 7- 41.

KIREJCZYK, Marta. Shaping users through the cultural and legal appropriation of in vitro ferilization. In: SAETNAN, Rudinow Ann; OUDSHOORN, Nelly; KIREJCZYK, Marta. Bodies of technology: Women's involvement with reproductive medicine. Georgia: Ohio State University Press. 2000. p. 183-206. 
LABORIE, Francoise. Les Femmes objets d'experimentation. Cahiers du Feminisme, Paris: Printemps, n. 59/60, p. 30-33, $1992 \mathrm{a}$. (Dossier, entretien).

. Rapports sociaux de sexe dans les nouvelles technologies de la reproduction. Cahiers du GEDISST. Paris: L'Hamattan, n. 3, 1992 b. p. 26-34

. Procréation artificielle: de quelle politique reproductive s'agit-il? Cahiers du GEDISST. Paris: IRESCO/GEDDISST/CNRS, n. 5, 1992c. p. $43-60$.

LABORIE, Francoise. La maternité à quel prix? Cahiers du Feminisme. Paris: Printemps, 1992. (Dossier, entretein).

- Novas tecnologias da reprodução: risco ou liberdade para as mulheres? Tradução de Vera P. ; Gisélia P. Revista de Estudos Feministas. Rio de Janeiro: CIEC/ECO/UERJ, v. 1, n.2, 1993. p. 435- 447.

Procréation artificielle: Santé des Femmes et des Enfants. Paris: Louvain- la- Neuve, Academia- Bruylant/ L'Harmattan; CNRS/IRESCO/ GEDISST, 1996. p. 477-500.

LABORIE, Francoise; AKRICH, Madeleine. De la contraception à l'enfantement. L'offre techonologique en question. Cahiers du Genre. Paris: Editions L'Harmattan, n. 25, p. 5-16, 1999. Coordonné par Madeleine AKRICH et Francoise LABORIE.

. Tecnologies de la reproduction humaine. In: HIRATA, Helena; LABORIE, Françoise; LE DOARE, Hélène; SENOTIER, Daniele. (Coords.). Dictionnaire critique du féminisme. Paris: PUF, 2000. p. 220-225. Politique D'aujourd'hui. 
OLIVEIRA, Fátima . Opressão de gênero, feminismo e bioética: “algumas considerações para o debate”. Rede de informação sobre bioética: bioética \& teoria feminista e anti-racista. Disponível em: < http://culturabrasil. art.br/RIB/DPBartigo1.htm>. Acesso em: 29 jun. 2000.

PHARO, Patrick. Nature, culture et significations dans la theories de l'homme. Paris/CNRS/CERSES. Notes de l'exposé du 9 octobre, 2001.

ROTANIA DE POZZI, Alejandra Ana .Vertientes valorativas actuales frente a las nuevas tecnologias reproductivas. In: SCAVONE, Lucila. Género y salud reproductiva en América Latina. Cartago, Costa Rica: LUR, 1999. p. 333-368.

ROUCH, Hélène. Nouvelles techniques de reproduction: de la différence à l'inégalité. In: HURTIG, Marie-Claude; KAIL, Michèle; ROUCH, Hélène. Sexe biologique et sexe social. Paris: CNRS, 2002. p. 245-255.

SAETNAN, Ann Rudinow. Women's involvement with reproductive medicine: introducing shared concepts. In: SAETNAN, Ann Rudinow; OUDSHOORN, Nelly; KIREJCZYK, Marta (eds.). Bodies of technology: women's involvement with reproductive medicine. Georgia: Ohio State University Press, 2000. p. 1-30.

TAIN, Laurence. Techiniques et acteurs: parcours différencies de femmes dans une démarche de fécondation in vitro. Cahiers du Genre. Paris: Éditions L'Harmattan, n. 25 (De la contraception à l'enfantement: L'offre technologique en question), p. 75-94, 1999. Coordonné par Madeleine AKRICH et Francoise LABORIE.

TAMANINI, Marlene. Novas tecnologias reprodutivas conceptivas à luz da bioética e das teorias de gênero: casais e médic@s no Sul do Brasil. 2003. 363 p. Tese (Doutorado no Programa Interdisciplinar em Ciências Humanas, Linha Estudos de Gênero) - Centro de Filosofia e Ciências Humanas, Universidade Federal de Santa Catarina, Florianópolis. 
. De sexo cronometrado ao casal infértil. In: GROSSI, Miriam; PORTO, Rozeli; TAMANINI, Marlene (orga). Novas tecnologias reprodutivas conceptivas: questões e desafios. Brasília: Letras Livres, 2003a. p. 123-136.

- Novas tecnologias reprodutivas conceptivas: o arquitetar da procriação entre o laboratório e o cronômetro. Anais da Semana de Tecnologia, CEFET-PR, v.1, n.1, 2004. Trabalho apresentado na Semana de Tecnologia em Curiba no GT Relações de Gênero e Tecnologia, Mesa gênero, tecnologia e saúde em 2003.

. Deslocamentos de gênero: a ordem tecnológica de ajuda a natureza nas relações do paternar e do maternar. Apresentado na V RAM, em dezembro de 2003. Disponibilizado pela Comunidade Virtual de Antropologia na seção "ARTIGO" http;//www.antropologia.com.Br/art/ arti13_vram_gt11.html em janeiro de 2004a.

Novas tecnologias reprodutivas conceptivas: bioética e controvérsias. Estudos Feministas. Florianópolis: CFH/CCE/UFSC, v. 12, n. 1 , de 2004. p. $73-107$.

TELLES, Fábio. Estadão. Desenvolvida Técnica para fecundação de óvulo sem esperma. Disponível em: <www.estadao.com.br/ciencia/ noticias/2001/jul/10/216.htm>

TESTART, Jacques. Des hommes problables: de la procréation aléatoire à la reproduction normative. Paris: Du Seuil, 1999.

TESTARD, Jacques; GODIN, Christian. Au bazar du vivant: biologie, médicine et bioéthique sous la coupe libérale. Paris: Du Seuil, 2001.

WARNOCK, Mary. Report of committee of inquiry into human fertilization and embriology. London: HMSO, 1984. 
VAN DER PLOEG, Irma. L'individualité féminine à l'épreuve des techonologies de reproduction. Cahiers du genre. Paris: L'Harmattan, n. 25 (De la contraception à l'enfantement: L'offre technologique en question), p. 95-121, 1999. 1999. Coordonné par Madeleine AKRICH et Françoise LABORIE. 
